\title{
Carta del presidente del XVI Congreso colombiano de Neumología y Cirugía de tórax
}

Horacio Giraldo Estrada, FCCP.

Apreciados Colegas y Amigos:

Para este año 2015 hemos escogido la hermosa región cafetera de nuestro país para llevar a cabo nuestro XVI Congreso colombiano de Neumología y Cirugía de tórax. Es la primera vez que se lleva a cabo en esta zona del país, y Pereira, la hermosa y amable capital del departamento de Risaralda, ofrece un clima medio muy agradable para desarrollar nuestras actividades académicas, así como un paisaje cafetero único, que junto con su tradicional cultura y arquitectura, permiten a los visitantes disfrutar de su gente, comercio, gastronomía e infraestructura hotelera.

En este congreso se harán varias innovaciones, que pensamos nos ubican a la vanguardia tecnológica de los congresos internacionales. Por ejemplo, la escarapela electrónica personalizada permitirá contabilizar en forma precisa la asistencia a las conferencias y servirá de manera automática como certificado de asistencia para los puntajes de educación médica continuada necesarios para el proceso de habilitación y acreditación en Neumología. Así mismo esta escarapela es una memoria USB que contendrá el programa del congreso, los resúmenes de los trabajos científicos y las revisiones de tema del año que se realizarán en forma simultánea en los diferentes salones en las primeras horas de la tarde. Se ha elaborado una aplicación para consultar el programa desde el teléfono celular o tableta, que permitirá también elaborar una agenda con las actividades a las que se desea asistir durante el congreso.

Tendremos con un importantísimo cartel de conferencistas internacionales y nacionales que nos permitirá poner al día nuestros conocimientos en los diferentes temas de la Neumología y Cirugía de tórax mediante conferencias magistrales, simposios y revisiones de tema. El primer día se realizarán cursos "de profundización" de temas específicos como broncoscopia, ventilación mecánica, sueño, prueba de ejercicio cardiopulmonar, Neumología ambiental y ocupacional, y función pulmonar, algunos de ellos con talleres prácticos. Los cursos de sueño y función pulmonar se harán en conjunto con la Asociación Latinoamericana del Tórax, ALAT.

Todos los cursos de profundización tendrán un libro de resúmenes de las conferencias para los asistentes a cada curso, y certificados de asistencia. Los libros sobrantes se podrán adquirir a partir del día siguiente al curso en el stand de la Asociación Colombiana de Neumología y Cirugía de Tórax.

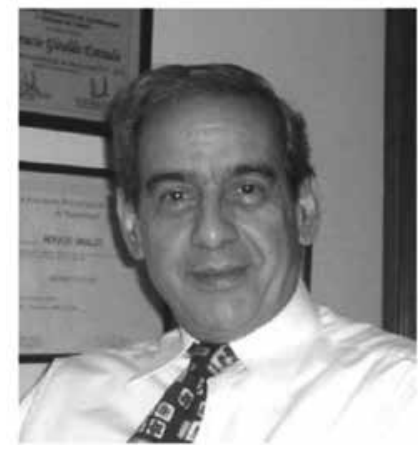

PRESIDENTE XVI CONGRESO COLOMBIANO DE NEUMOLOGÍA Y CIRUGÍA DE TÓRAX

Correo electrónico: hgiraldoe@yahoo.com 
Se expondrán 15 trabajos científicos para concurso y 92 pósters que se presentarán y discutirán también en forma verbal durante el congreso.

Se contará con un salón de Miembros de la Asociación y Conferencistas, así como otro salón confortable para todos los asistentes que deseen tener un momento de descanso durante las actividades académicas del día, donde tendrán acceso a Internet, computadoras, refrescos y a la posibilidad de interactuar con conferencistas nacionales y extranjeros.

La visita al stand de nuestros patrocinadores es parte importante del congreso, por lo cual se ha diseñado la "Trivia del pulmón", un ejercicio de preguntas médicas y respuestas que deberán obtenerse en cada stand con el fin reclamar un magnífico y útil obsequio.
El congreso se clausura el sábado 10 de octubre, y se dejará tiempo para los que deseen tomar un tour por la zona cafetera el 11 de octubre, el cual incluye visita al Mariposario, al Orquidiario y almuerzo en una finca cafetera, donde además se hará un recorrido para conocer los cafetales, el proceso del mejor café suave del mundo, y la forma ideal de prepararlo y consumirlo. Por razones de adherencia a los lineamientos de ética de Afidro, el Congreso no podrá patrocinar este tour, pero se podrá obtener a precio especial de grupo con trasporte exclusivo para quienes lo compren en el marco del Congreso.

Les deseamos una muy feliz estancia en Pereira, y que disfruten de la nutrida y variada agenda académica que hemos diseñado para este evento. 